\title{
OPEN Nerve Growth Factor (NGF) modulates in vitro induced myofibroblasts by highlighting a differential protein signature
}

\author{
Graziana Esposito ${ }^{1}$, Bijorn Omar Balzamino ${ }^{1}$, Egidio Stigliano ${ }^{2,3}$, Filippo Biamonte ${ }^{2,3}$, \\ Andrea Urbani ${ }^{2,3}$ \& Alessandra Micera ${ }^{1 \bowtie}$
}

We previously described the profibrogenic effect of NGF on conjunctival Fibroblasts (FBs) and its ability to trigger apoptosis in TGF $\beta 1$-induced myofibroblasts (myoFBs). Herein, cell apoptosis/ signalling, cytokines' signature in conditioned media and inflammatory as well as angiogenic pathway were investigated. Experimental myoFBs were exposed to NGF $(0.1-100 \mathrm{ng} / \mathrm{mL})$, at defined timepoint for confocal and biomolecular analysis. Cells were analysed for apoptotic and cell signalling activation in cell extracts and for some inflammatory and proinflammatory/angiogenic factors' activations. NGF triggered cJun overexpression and phospho-p65-NFkB nuclear translocation. A decreased Bcl2:Bax ratio and a significant expression of smad7 were confirmed in early AnnexinVpositive myoFBs. A specific protein signature characterised the conditioned media: a dose dependent decrease occurred for IL8, IL6 while a selective increase was observed for VEGF and cyr61 (protein/ mRNA). TIMP1 levels were unaffected. Herein, NGF modulation of smad7, the specific IL8 and IL6 as well as VEGF and cyr61 modulation deserve more attention as opening to alternative approaches to counteract fibrosis.

The prolonged survival of myofibroblasts (myoFBs) characterize the pathological process of fibrosis ${ }^{1,2}$. MyoFBs are transient cells arising from quiescent fibroblasts (FBs); at injured zone FBs are exposed to proinflammatory cytokines, growth factors and extracellular matrix (ECM) products/mediators ${ }^{2}$. A defined deletion of myoFBs is vital to ensure a proper tissue healing (physiological remodeling) and the restoration of local function, while the aberrant apoptosis can account for excessive scarring and overt fibrosis ${ }^{2,3}$. Thus the mechanisms of myoFB persistence still require attention.

Nerve Growth Factor (NGF) promotes wound-healing and regulates ECM remodeling, allowing a wellbalanced tissue repair and recovery of functional activity ${ }^{4,5}$. This pleiotropic factor orchestrates crucial cell activities (proliferation, stimulation, differentiation and survival) on structural and functional cells belonging to the endocrine, immune and visual systems ${ }^{4}$. NGF binds to both specific (trkA ${ }^{\mathrm{NGFR}}$ ) and/or pan-neurotrophin $\left(\mathrm{p} 75^{\mathrm{NTR}}\right.$ ) receptors to promote (autocrine/paracrine) downstream effects on the surrounding epithelial, endothelial, stromal and immune (mast cells, eosinophils, B/T cells, macrophages) cells ${ }^{6-10}$. Previous studies from our laboratory described the profibrogenic effect played by NGF on healthy-control primary cultures of conjunctival Fibroblasts (FBs), mainly expressing trkA ${ }^{\mathrm{NGFR}}$, highlighting NGF ability to trigger apoptosis in the in vitro TGF $\beta 1$-induced myofibroblast model expressing both trkA $\mathrm{NGFR}^{\mathrm{N}} \mathrm{p} 5^{\mathrm{NTR} 11}$.

In visual system, the topical (eye-drop) NGF application improved corneal sensitivity and promoted corneal epithelial healing in both moderate and severe neurotrophic keratitis as well as in neurotrophic or autoimmune corneal ulcers $^{10,12}$. A crosstalk between epithelial cell and $\mathrm{FB} /$ myoFB cell balance accounts for the correct tissue remodeling, sustained by the immune related cell pattern ${ }^{6}$. Direct paracrine signaling from early and late apoptotic cells in concert with immune cells (macrophages, neutrophils, infiltrating eosinophils and tissue resident mast cells) can also drive fibrotic outcomes, by a specific release of factors inside fibrotic tissue ${ }^{6}$. Therefore, alternative approaches, other than steroid and proper antifibrotic drugs, have been suggested for counteracting overt fibrotic response and promoting a "remodeling again" inside fibrotic tissues ${ }^{13}$. Few reports highlighted

\footnotetext{
${ }^{1}$ Research and Development Laboratory for Biochemical, Molecular and Cellular Applications in Ophthalmological Sciences, IRCCS-Fondazione Bietti, Rome, Italy. ${ }^{2}$ Fondazione Policlinico Universitario A. Gemelli, IRCCS, 00168 Rome, Italy. ${ }^{3}$ Istituto di Biochimica e Biochimica Clinica e Istituto di Anatomia Patologica, Università Cattolica del Sacro Cuore, 00168 Rome, Italy. ${ }^{\circledR}$ email: alessandra.micera@fondazionebietti.it
} 


\begin{tabular}{|c|c|c|c|c|}
\hline Target (Human) & Dilution & Host & Specificity (marker) & Source \\
\hline \multicolumn{5}{|c|}{ A: Biochemical analysis } \\
\hline $\mathrm{p} 75^{\mathrm{NTR}}$ & $1: 100$ & Goat & Pan-neurotrophin p75 $5^{\mathrm{NTR}}$ & Santa cruz \\
\hline aSMA & $1: 500$ & Mouse & Smooth muscle actin alpha & Sigma \\
\hline p65NFkB & $1: 100$ & Goat & Nuclear translocation factor & Santa cruz \\
\hline phospho p65NFkB & $1: 50$ & Goat & Ser63-Nuclear translocation factor & $\begin{array}{l}\text { Cell Signaling Technology, Leiden, } \\
\text { Netherlands }\end{array}$ \\
\hline Annexin V & 1:100 & Mouse & Early apoptotic & Biolegend \\
\hline cJun & $1: 1000$ & Mouse & c-Jun & Cell Signaling \\
\hline Actin & $1: 1000$ & Mouse & Cytoskeleton & Sigma \\
\hline Tubulin & $1: 1000$ & Mouse & Cytoskeleton & Santa Cruz \\
\hline Target (Human) & Accession & Sequence (left primer) & Tm/amplicon & \\
\hline \multicolumn{5}{|c|}{ B: Molecular analysis } \\
\hline $\mathrm{Bcl} 2$ & BC027258 & ctcccaatactggctctgtc & $56^{\circ} \mathrm{C} / 111$ bps & \\
\hline Bax & BM673184 & tgccagcaaactggtgct & $56^{\circ} \mathrm{C} / 129$ bps & \\
\hline Smad7 & AF015261 & ccaactgcagactgtccaga & $60^{\circ} \mathrm{C} / 107$ bps & \\
\hline Cyr61 & BC009199 & cacccttctccacttgacc & $58^{\circ} \mathrm{C} / 163$ bps & \\
\hline VEGF-A & AF022375 & tgacagggaagaggaggaga & $59^{\circ} \mathrm{C} / 141$ bps & \\
\hline GAPDH & BC013310 & gaaggggtcattgatggcaac & $63^{\circ} \mathrm{C} / 100 \mathrm{bps}$ & \\
\hline $\mathrm{H} 3$ & AC239868 & gtctgcaggctggcatagaag & $61^{\circ} \mathrm{C} / 100$ bps & \\
\hline
\end{tabular}

Table 1. Antibodies and primers overview. (A) primary antibodies used for western and immunofluorescence assay. (B) Summary of name, for/rev sequence (5' to 3'), PCR product size (amplicons in bps), annealing conditions and GenBank Accession Numbers of each gene investigated. Amplification profile: hot start activation $\left(95^{\circ} \mathrm{C} / 15 \mathrm{~min}\right) ; 39$ cycles: den. at $94^{\circ} \mathrm{C} / 10 \mathrm{~s}$-ann. At $58^{\circ} \mathrm{C} / 15 \mathrm{~s}$-ext. at $72{ }^{\circ} \mathrm{C} / 10 \mathrm{~s}$; melting curve recording $55^{\circ} \mathrm{C}$ to $95^{\circ} \mathrm{C}$ with one fluorescence reading every $0.5^{\circ} \mathrm{C}$; further ext. $75^{\circ} \mathrm{C} / 5 \mathrm{~min}$.

the possibility that angiogenesis or vascular regression might counteract the overt fibrosis: early vascular outgrowth or vascular apoptotic cell presence might represent regulators of fibrosis ${ }^{14}$. NGF was found to increase VEGF expression in different cell types including FBs/myoFBs, and in turn VEGF-D was found to stimulate myofibroblast growth, migration and collagen synthesis, opening to other routes to regulate tissue remodeling and fibrosis ${ }^{14-16}$. The cellular matrix protein cyr61 (CCN1), a multifunctional matricellular protein dynamically involved in ECM remodeling, enhances TGF $\beta 1 /$ SMAD profibrotic signaling in fibroblasts and contributes to lung fibrosis and angiogenesis ${ }^{17}$.

Since FBs represent the main target/effector cells of tissue remodeling and NGF is known to sustain the in vitro myoFBs development and modulate apoptosis, further NGF effects model were investigated on this myoFB, in terms of cell signal transduction (cJun, p65-NFkB and smad7), cytokines' signature in conditioned media and remodeling/angiogenic pathways.

\section{Materials and methods}

Routine reagents. Plasticware and analytic grade reagents were purchased from Starlab (Milan, Italy), Euroclone (Milan, Italy), ICN Biochemicals (Costa Mesa, CA), Sigma-Aldrich (St. Louis, CA, USA) and Carlo Erba (Milan, Italy), otherwise specified in the text. Sterile tissue culture plasticware was obtained from NUNC (Roskilde, Denmark) and medium were from Euroclone (Milan, Italy). RNAfree MilliQ water (DirectQ; MerckMillipore, Vimdrone, Milan) and home-made buffers (Phosphate-Buffered Saline, PBS: $10 \mathrm{mM}$ phosphate $\mathrm{pH}$ 7.5 in $0.9 \%$ saline; Tris-Buffered Saline, TBS: $50 \mathrm{mM}$ Trizma pH 7.5 and $160 \mathrm{mM} \mathrm{NaCl}$ ) for biomolecular analysis were daily autoclaved.

Conventional and p75 NTR siRNA cultures: NGF treatments. The study followed the guidelines of the Declaration of Helsinki and complied with the ARVO Statement in Ophthalmic and Vision Research for research. The study was approved by the intramural scientific committee of IRCCS-Fondazione Bietti. Human conjunctival FBs provided by Innoprot $(n=3$; Bizkaia, Spain) were expanded in complete DMEM (10\% Fetal Bovine Serum (FBS), $1 \mathrm{mM}$ Glutamine and $1 \%$ pen/strep mix $)^{8,9}$. Confluent $48 \mathrm{~h}$-serum starved monolayers were exposed to $10 \mathrm{ng} / \mathrm{mL}$ TGF $\beta 1$ (PeproTech EC, Ltd., London, UK) over 3 days, to develop "in vitro induced" myofibroblast (myoFBs). Induced myoFBs were replaced at high density in 24-well culture plates (on coverslips) for microscopy as well as in 24-well or 6-well plates for biomolecular analysis. Cells were exposed to increasing (1-100 ng/mL; $\beta$-NGF Grade-I; Alomone Labs Ltd, Jerusalem, Israel) NGF concentrations in 0.1\% FBS-DMEM, over 15 min-30 min-3 h-6 h-24 h for respectively molecular and biomolecular analysis. After stimulation, cells were washed with Hank's Balanced Sodium Solution (HBSS, Euroclone) and harvested for biomolecular analysis or quickly fixed for microscopical evaluations. Untreated cells $(0 \mathrm{ng} / \mathrm{mL})$ were provided for each experiment route, to minimize biochemical changes alongside subculturing.

Myofibroblasts (30-50\% confluence) were transfected with $200 \mathrm{nM}$ antisense p $75^{\mathrm{NTR}}$ oligonucleotides (for sequence details see Table 1 Ref.7 ) in lipofectamine RNAiMAX (ThermoFischer, Waltham, MA USA), according 
to a standard protocol with minor revisions ${ }^{11}$. After 3 days, different doses of NGF were added to both siRNA and sham cultures to estimate growth and morphology after $24 \mathrm{~h}$. The neutralization has been confirmed by immunofluorescence of $\mathrm{p} 75^{\mathrm{NTR}}$ protein expression.

Double immunofluorescent analysis. Attached cells (monolayers on coverslips) were washed with HBSS, post-fixed with buffered-PFA (2\% paraformaldehyde in autoclaved PBS, quenched with $50 \mathrm{mM} \mathrm{NH}_{4} \mathrm{Cl}$ and briefly blocked/permeabilized in $0.8 \%$ BSA and $0.3 \%$ Triton X100 in PBS. Incubations with aSMA (1:100; clone AC-15); AnnexinV ${ }^{\text {FITC }}$ (1:100; Biolegend, San Diego, CA); goat anti-human p65 subunit of NF-kB (referred as p65NFkB; sc-10741); goat anti-human phospho-Ser63-p65NFkB (referred as phospho-p65NFkB; \#9261) and goat anti-human $\mathrm{p} 75^{\mathrm{NTR}}(1 \mu \mathrm{g} / \mathrm{mL}$; sc-6188), as listed in Table 1A, were followed specie-specific fluorophoresconjugated secondary antibodies (1:300/1:500) including Cy2 (green) or Cy5 (blue). Irrelevant isotype-matched IgG antibodies or omission of the first antibodies (Vector Laboratories, Inc., Burlingame, CA) were used as controls for the channel series or background subtraction. Coverslips were placed upside-down on glasses by antifading mounting medium (Vectamount, Vector) for analysis. Single acquisitions and merged staining's were performed according to fluorescent emission wavelength.

Confocal image capturing and IntDen analysis. Dry and oil immersion images were acquired by C1 software connected to TE-2000U inverted confocal microscope equipped with lasers or with microscope equipped with epifluorescence and software for image acquisition (Nikon, Tokyo, Japan). For image capturing, $40 \times$ and $60 \times /$ oil immersion objectives were used, and images were saved/converted into 8-bit TIFF format and subjected to Integrated densitometric (IntDen) analysis (Image J v1.43; NIH -http://rsb.info.nih.gov/ij/), according to a standard procedure ${ }^{18}$. Fluorescence Intensity (FI) was determined by measuring the average fluorescent signal per pixel within a fixed area (round frame) placed over the relevant area of the cell. Averages (means \pm SD) were calculated for each data set, using GraphPad Software (Prism 8, San Diego, CA). Representative images were assembled in figures by using the Adobe Photoshop 2020 22.0.0 software release (Adobe Systems Inc., San Jose, CA). Minimal adjustments were made to images to obtain the best quality of presentation.

Western blotting analysis. Monolayers ( $10^{6}$ single cells per well) were prewashed in ice-cold HBSS, cells were detached with a trypsin solution and harvesting was performed in 10\% FBS-HBSS to neutralize enzyme activity. Pellets $(3500 \mathrm{rpm} / 3 \mathrm{~min})$ were treated with $70 \mu \mathrm{L}$ lysis buffer $(20 \mathrm{mM}$ Tris, $\mathrm{pH} 7.5,150 \mathrm{mM} \mathrm{NaCl}, 1 \mathrm{mM}$ EDTA, $1 \%$ Triton X-100, $10 \%$ glycerol, $1 \mathrm{mM} \mathrm{NaF}, 1 \mathrm{mM} \mathrm{Na}_{3} \mathrm{VO}_{4}$ and a Protease Inhibitor Cocktail (Pierce Biotechnology, Rockford, IL). Cell protein extracts $\left(4^{\circ} \mathrm{C}\right.$ for $\left.20 \mathrm{~min}\right)$ were centrifuged $(15,000 \mathrm{rpm}$ for $10 \mathrm{~min}$; $4{ }^{\circ} \mathrm{C}$ ) to discard debris and cytosolic/nuclear protein extracts were simultaneously produced by using the NEPER Nuclear and Cytoplasmic Extraction Reagents kit (78,833; Pierce), following the protocol recommended by the manufacturer.

Cytosolic and nuclear sub-fractions ( $3 \mu \mathrm{L}$ from each sample) were subjected to A280 quantification against lysozyme referring protein (NanoDrop 1000 Spectrophotometer, Thermo Fisher Scientific, MA, USA). Protein extracts were stored at $-20^{\circ} \mathrm{C}$ until SDS-PAGE separation and immunoblotting analysis. Appropriate normalized aliquots were prepared for each sample to assure only one freeze-thaw cycle.

Normalized extracts (15-30 $\mu$ g protein) were diluted in Laemmli sample buffer (62.5 mM Tris, pH 6.8, 25\% glycerol, $2 \%$ SDS, $0.01 \%$ bromophenol blue and $5 \%$ B-mercaptoethanol), heated to $95{ }^{\circ} \mathrm{C}$ for 5 min, loaded on precasted $4 \% / 7.5 \%$ or $10 \%$ gradient polyacrylamide minigels and run at $150 \mathrm{mV}$ to frontline in electrophoresis buffer (all from Bio-Rad, Hercules, CA). Bands were transferred (15 mV/15 min for 2 membranes) onto nitrocellulose membranes (protein high affinity; GE-healthcare, Chicago, USA) in appropriate transfer buffer ( $48 \mathrm{mM}$ Tris $\mathrm{pH}$ $6.8,39 \mathrm{mM}$ glycine, $0.00375 \%$ SDS and $20 \%$ methanol) by using the semidry transblotting procedure (Invitrogen, California, USA). For immunoblotting, membranes were washed in tris-buffered saline (TBS: $50 \mathrm{mM}$ TrisHCl and $0.9 \% \mathrm{NaCl} ; \mathrm{pH} 7.5$ ), blocked in TBS containing $5 \%$ non-fat dry milk and $0.03 \%$ Tween-20 (benchtop/60 min) and probed $\left(18 \mathrm{~h} / 4^{\circ} \mathrm{C}\right)$ with anti-human c-Jun (1:1000; \#9162); p65NFkB (1:1000) and phospho-p65NFkB (1:700) all listed in Table 1A. After washing in TBS, membranes were incubated with horseradish peroxidaseconjugated goat anti specie-specific IgG antibodies (1:20,000; Jackson ImmunoResearch) under gentle rotation $(60 \mathrm{~min} / 300 \mathrm{rpm})$. The immunolabeled bands were visualized after incubation with enhanced chemiluminescent ECL Pico Western Bot solution (Pierce) and digital capturing by the 1D Kodak Image Analysis Software (Kodak 550 Imager station; Eastman Kodak Company, Sci. Imaging Systems, Rochester, NY). After acquisitions, membranes were treated at $56^{\circ} \mathrm{C}$ for $60 \mathrm{~min}$ in stripping solution $(62.5 \mathrm{mM}$ Tris pH 6.7 containing $2 \%$ SDS and $100 \mathrm{mM} 2$-mercaptoethanol) and re-probed with actin or tubulin to confirm equal protein loading. Digital images were subjected to densitometric analysis and final images were assembled with Adobe photoshop 2020.

Ella microfluidics-based platform. Specific expression of Cyr61, IL6, IL8, TIMP1 and MMP9 was assessed by using the multiplex Ella platform. Briefly, 1:2 diluted samples were loaded on to the cartridge, according to a standard procedure provided by the manufacturers (Protein Simple, CA, USA). All steps in the procedure were run automatically by the instrument with no user activity. Cartridges include a built-in lotspecific standard curve for the defined protein. The obtained data were displayed as $\mathrm{pg} / \mathrm{mL}$ and automatically calculated by the internal instrument software.

Chip-based protein microarrays. Conditioned media from myoFBs were hybridized in chip arrays and labeled according to the manufacturer's instructions (G-series arrays; Ray Biotech, Norcross, CA). Each cy3labeled treated/untreated sample was combined with an equal amount of pooled cy5-labeled common reference and $70 \mu \mathrm{L}$ mixture (well/chip) was hybridized for $18 \mathrm{~h}$ at $4{ }^{\circ} \mathrm{C}$. After washes under stringency, the glass slides 
were washed once in MilliQ water to remove salts and quickly spun to dry the chips. Slides were analyzed in parallel: double fluorescence signals were acquired with the GenePix 4100 microarray scanner (Molecular Devices LLC, Sunnyvale, CA) equipped with the GenePix Pro 3.0 software (Axon Instruments, Foster City, CA). Data were expressed as ratio (treated/untreated signal).

RNA extraction, cDNA synthesis and relative real-time PCR. Total RNA was extracted from 6-well plates cells according to the TRIfast technique (Euroclone), treated with DNAseI (AB1709; Ambion Inc., Austin, TX), spectrophotometrically analyzed for quantification and purity (260/280 ratio; Nanodrop A1000 Spectrophotometer; Celbio, Milan, Italy). A further RNA quality assessment was carried out on randomly selected RNA extracts in a $1 \%$ agarose (Promega, Milan, Italy) gel supplemented with Ethidium Bromide (ICN). Only samples with $260 / 280>1.8$ were used for amplification studies.

cDNA was generated from $3 \mu \mathrm{g}$ total RNAs by using the GoScript standardized procedure (Promega) in the presence of random hexamers (Promega), in a OneCycler programmable thermocycler (Peqlab; VWR Radnor, Pennsylvania, USA). For amplifications, $3 \mu \mathrm{L}$ cDNAs for target gene and $1 \mu \mathrm{L} c D N A s$ for referring ones were amplified in a $20 \mu \mathrm{L}$ final volume of SYBR Green PCR mixture (Applied Biosystems, Foster City, CA), using the Opticon2 real time thermocycler (MJ Research, Watertown, MA). Amplification profile was: one cycle of $95^{\circ} \mathrm{C} / 15 \mathrm{~min}$ initial denaturation followed by $35-45$ cycles at $95^{\circ} \mathrm{C} / 30 \mathrm{~s}$ (denaturation), $55-60{ }^{\circ} \mathrm{C} / 25 \mathrm{~s}$ (annealing) and $72{ }^{\circ} \mathrm{C} / 30 \mathrm{~s}$ (elongation), followed by fluorescence monitoring at $60-90^{\circ} \mathrm{C}, 0.01^{\circ} \mathrm{C}$ for $0.3 \mathrm{~s}$ and further elongation at $72^{\circ} \mathrm{C} / 5 \mathrm{~min}$. Negative and positive controls were run in parallel, according to a standard procedure. The specific primer pairs, the accession number and the length of amplicons are shown in Table $1 \mathrm{~B}$ (synthesized by Eurofin MWG, Ebersberg, Germany).

Only normalized samples were amplified and cycle threshold $(\mathrm{Ct})$ values from good melting curves were used for analysis in the REST software ${ }^{19}$. Relative gene expression was calculated as the expression level of target gene with respect to that of referring genes (H3 and/or GAPDH), considering both treated vs. untreated cells. As fold-change ratios were expressed in 2-log, only increase/decrease over 2 were considered of interest in the statistical evaluation.

Statistical analysis. Experiments were performed in triplicate, starting from $n=3$ primary sets expanded and used in the 5th-7th generation range, and analysed for three times to validate results. Controls (without NGF stimulation) were carried out in every plate and each generation. Descriptive statistic and graphics were performed using the GraphPad Prism 8.01 (GraphPad, San Diego, CA). The standard deviation (SD) and Standard Error from the Mean (SEM) were calculated to assess the variations between different treatments under the same conditions (untreated cells). Data were subject to statistical significance by one-way analysis of variance (ANOVA) using the StatView II Software (Barckley, CA). ANOVA was coupled to post-hoc analysis performed using Tukey's test between subgroups and with respect to untreated cells). All $p$ values $\leq 0.05$ were considered as significant and depending on post-hoc analysis, appropriate asterisks were used in panels as follows: ${ }^{\star} p<.05$; ${ }^{* *} p<.01$ and ${ }^{* * *} p<.001$ (highly significant). For chip array analysis, a $p<.0083$ was used together with a limit of 2 -folds. Data are mean \pm SD (text) and mean \pm SEM (figures), and error bars were calculated from at least three independent experimental sets.

\section{Results}

A flow chart of overall experimental procedure is shown in Fig. 1A. High density replated and serum-starved confluent TGF $\beta 1$-induced myoFBs (herein shorten as myoFBs) were exposed to single or chronic increasing NGF concentration (0-100 ng/mL), over $15 \mathrm{~min}-30 \mathrm{~min}-3 \mathrm{~h}-6 \mathrm{~h}-24 \mathrm{~h}$ (protein/mRNA) time-point sets. Untreated myoFBs were used as control and carried out at each set of experiments. The typical spindle-appearance and the $\mathrm{p} 75^{\mathrm{NTR}}$ (green) and $\alpha \mathrm{SMA}$ (blue) expression on red nuclear counterstaining are visible in Fig. $1 \mathrm{~B}$.

NGF activates p65NFkB / cJun molecules in AnnexinV positive myoFBs. NGF induced a dosedependent increase of phospho-p65NFkB protein in AnnexinV positive myoFBs. The quantification of immunoreactivity (Integrated Density; IntDen) is shown in the histogram (Fig. 1C). IntDen values are \% over control (sister untreated myoFBs). Representative confocal images are shown in Fig. 1C reporting both single (specific) and double (merge) immunostainings. The merge visualization in the upper row (Fig. 1C) highlight that NGF exposed myoFBs positively stained for phospho-p65NFkB (blue/cy5) and AnnexinV (green/FITC). Single immunoreactions for phospho-p65NFkB (middle row, blue/cy5) and AnnexinV (lower row; green/FITC) are shown below. This p65NFkB expression was associated with a significant increase of enlarged, nuclear condensed cells, especially after repeated NGF treatment (see white arrows). TGF $\beta 1$ by itself did not trigger significant $\mathrm{p} 75^{\mathrm{NTR}}$ expression nor AnnexinV, retaining a high trkA $\mathrm{NGFR}^{\mathrm{N}} \mathrm{p} 75^{\mathrm{NTR}}$ ratio (data not shown). At the same time, NGF exposure induced the activation of cJun and NFkB pathways in a time-dependent fashion. Data from western blotting analysis corroborated the confocal ones, at least at $100 \mathrm{ng} / \mathrm{mL}$ NGF exposure. As shown in Fig. 1D, NGF triggered the cJun protein expression in a time-dependent fashion, as compared to untreated ones ( ${ }^{\star *} p<.001$ vs. untreated cell extracts; ANOVA-Tukey Kramer post-hoc). In line, p65NFkB protein signal also increased in a time-dependent fashion $\left({ }^{*} p<.05\right.$ vs untreated cell extracts; ANOVA-Tukey Kramer post-hoc; Fig. 1E). Original immunoblots for cJun and p65NFkB are visible in the supplementary Fig. S1.

NGF promotes nuclear translocation of phosphorylated p65NFkB in receptive myoFBs. Immunoreactivity for p65NFkB and p $75^{\mathrm{NTR}}$ (merge, left panel) was observed in myoFBs exposed to repeated $100 \mathrm{ng} /$ $\mathrm{mL}$ NGF stimulation (Fig. 2A). Single staining for $\mathrm{p} 75^{\mathrm{NTR}}$ (middle panel/green/cy2) and p65NFkB (right panel/ blue/cy5) are also shown. MyoFBs showed a significant increase in phospho-p65NFkB expression at both cyto- 
A

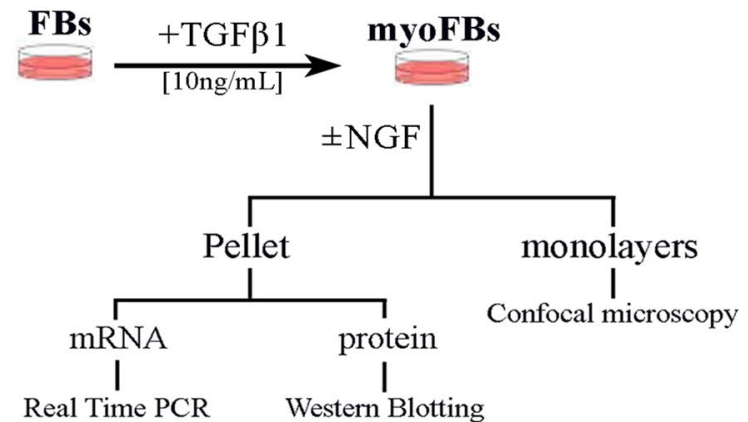

B

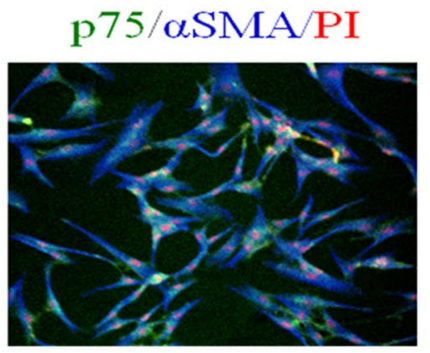

C
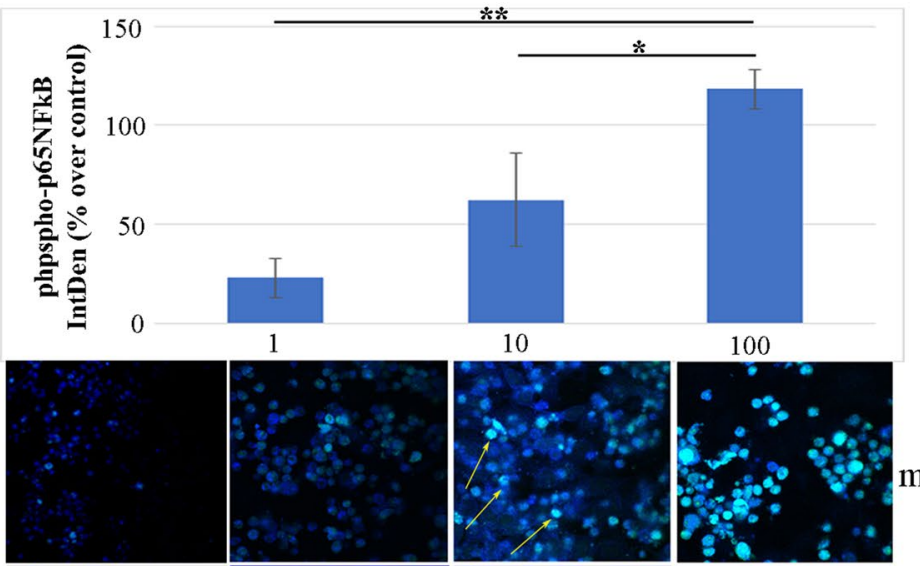

merge
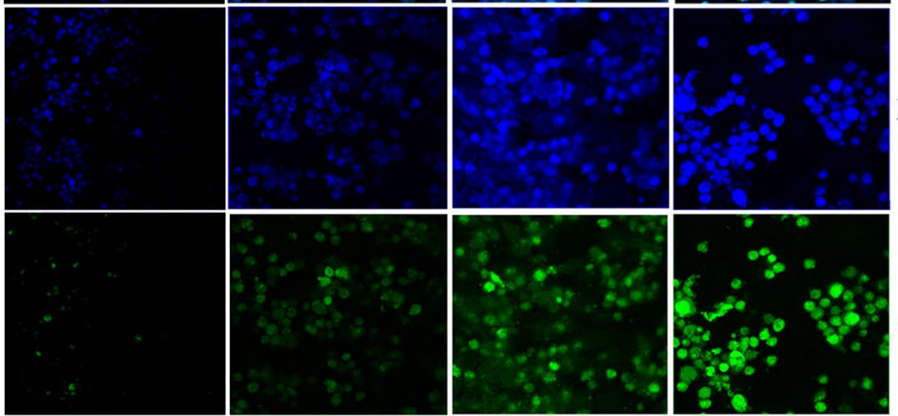

p65

D
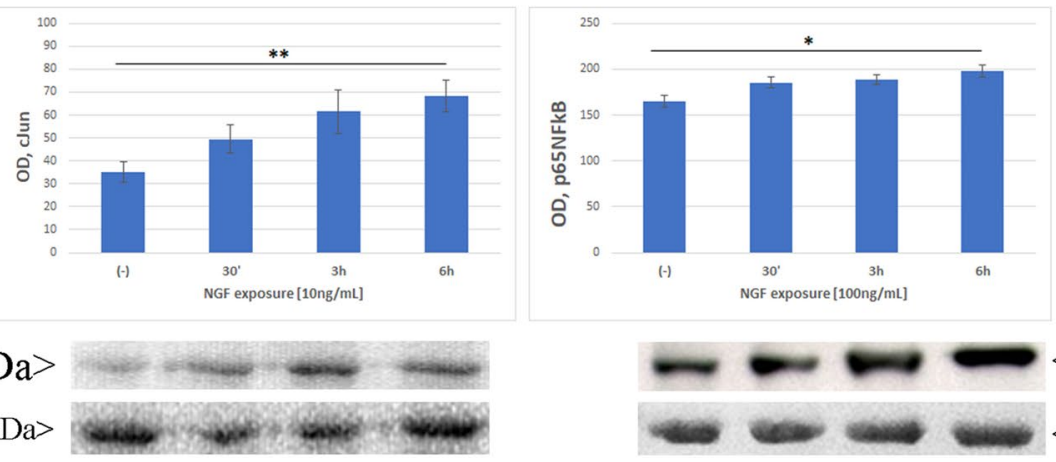

E

\section{$40 \mathrm{kDa}>$}

tubulin $55 \mathrm{kDa}>$

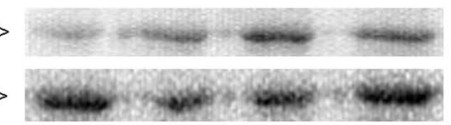

Figure 1. Overall experiment and cell features. (A) Flow chart summarizing the TGF $\beta 1$-induced myoFB and NGF exposures/ analysis. Stimuli and timing are highlighted. (B) Representative confocal microscopy image showing co-expression of p75 ${ }^{\mathrm{NTR}}$ (cy2/ green) and aSMA (cy5/blue) on nuclear stained myoFBs (Propidium Iodide/red) (magnification, $\times 200$ ). (C) NGF triggers p65NFkB expression in AnnexinV positive myoFBs. Dose-dependent increase of total p65NFkB is shown over $24 \mathrm{~h}$, as detected by quantitative Imaging analysis (IntDen) on single-channel p65NFkB (cy2/green) confocal images. Immunoreactivity for AnnexinV (cy2/green) and p65NFkB (cy5/blue) in myoFBs as shown in the overlay row and the single panels below reported, all with respect to NGF exposure concentrations. Arrows in $10 \mathrm{ng} / \mathrm{mL}$ NGF (merge) panel point at some coexpressing cells: NGF effect is detectable as soon as at $10 \mathrm{ng} /$ $\mathrm{mL}$ and significantly increase at $100 \mathrm{ng} / \mathrm{mL}$ doses. (DE) Time-dependent histograms and cropped blots, showing expression of cJun and p65NFkB, at the specific molecular weight for cJun $(40 \mathrm{kDa} ; \mathbf{D})$ and total p65NFkB $(65 \mathrm{kDa} ; \mathbf{E})$ above the related tubulin $(55 \mathrm{kDa})$ and actin $(42 \mathrm{kDa})$ housekeeping ones, from NGF exposed myoFBs over a timing of $30 \mathrm{~min}, 3$ and $6 \mathrm{~h}$. Densitometric analysis was performed specifically on the cropped image (see panel), resulting from the original immunoblot (see Fig. S1), to avoid any artefact in acquisition and data were expressed as compared to untreated ones. Minor brightness/contrast adjustment were performed by photoshop for better image presentation (cropped panel). ANOVA analysis followed by Tukey Kramer post-hoc; Sign: ${ }^{\star} p<.05$; magnification, $\times 400$. 
NGF, 100ng/mL

A
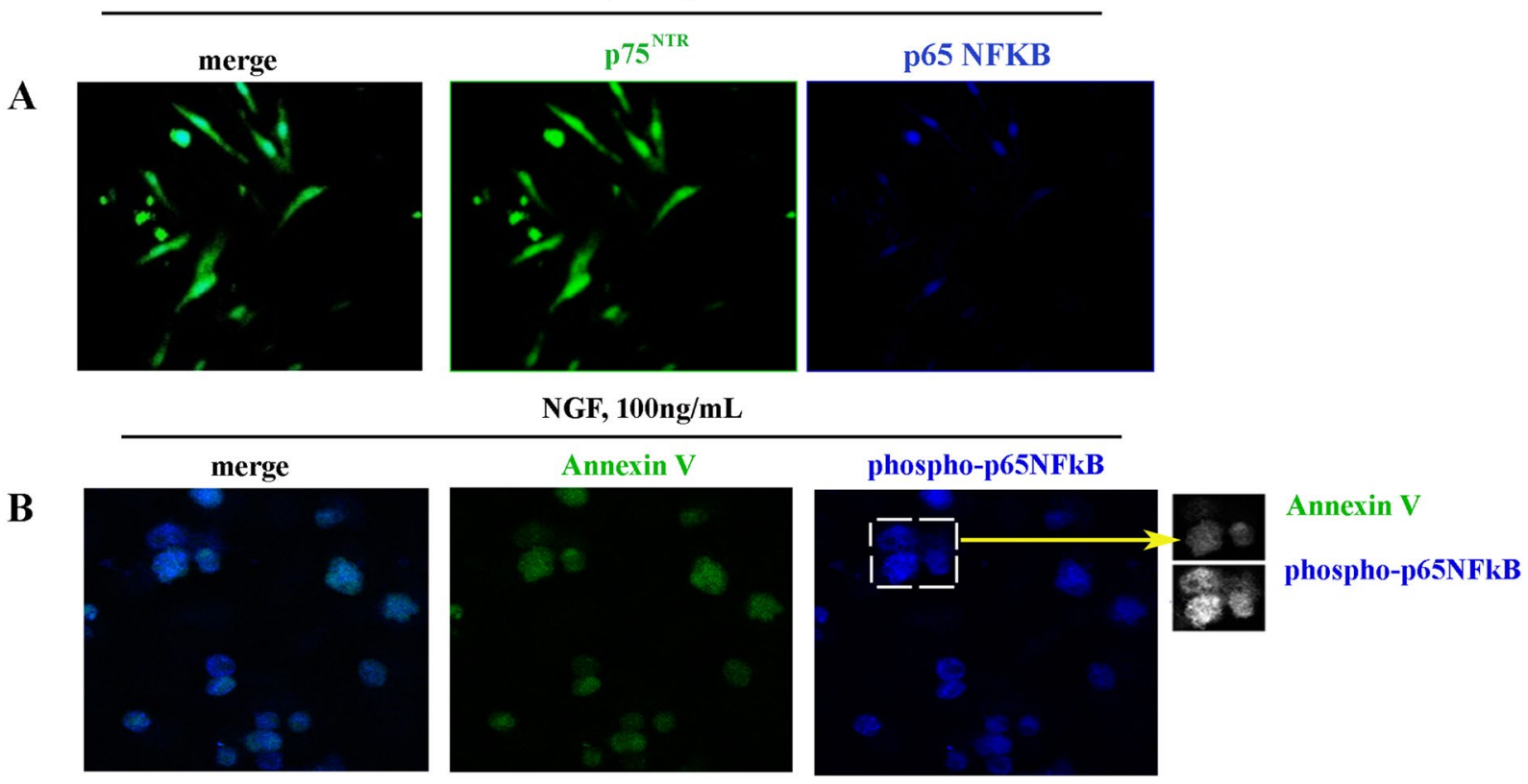

C
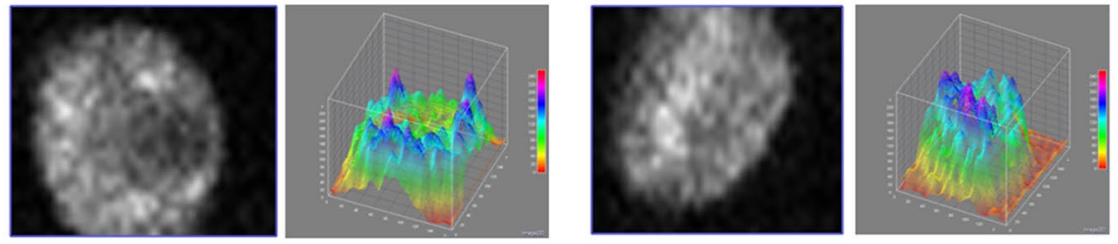

D

E

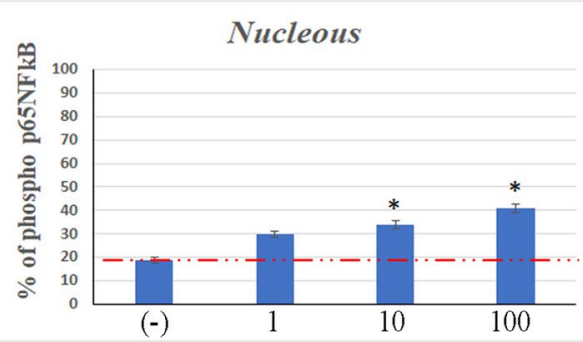

$(-)$

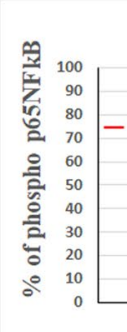

Cytoplasmatic

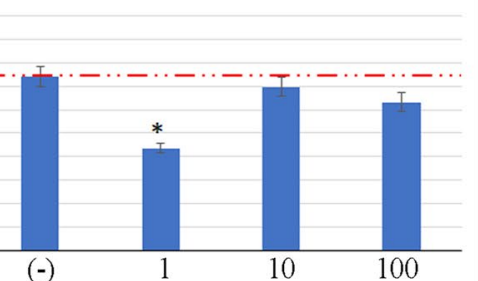

F

\section{$<$ ng/mL NGF \\ $<65 k D a$ pNFkB \\ $<42 \mathrm{kDa}$ actin}

pNFkB 65kDa>

actin $42 \mathrm{kDa}>$
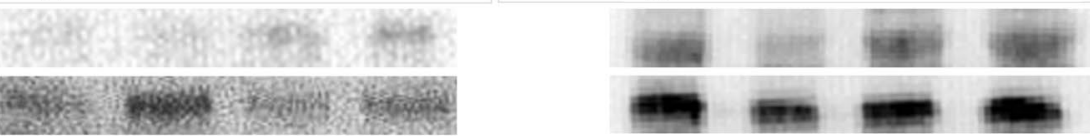

Figure 2. NGF triggers p65-NFkB phosphorylation and nuclear translocation. Cells were exposed to repeated (chronic) $100 \mathrm{ng} / \mathrm{mL}$ stimulation and sampled at $24 \mathrm{~h}$ for phosphorylation and translocation analysis of p65NFkB. (A) Representative confocal image showing the co-expression of $\mathrm{p} 75^{\mathrm{NTR}}$ and p65NFkB in induced myoFBs (yellow; overlay/left panel). (B) Representative higher magnification overlay images (left panel) displaying AnnexinV-positive myoFBs (cy2/green; labelling the outset leaflet of the plasma membrane) with nuclear localization of phosphop65NFkB (cy5/blue). Single acquisitions are shown in middle (AnnexinV; cy2/green) and right (phospho-p65NFkB; cy5blue) panels. Gray level images from a selected cell in right (B) panel, as pointed by arrow. (C,D) Representative expression of different intracellular localization expressed as pseudocolor carried out by single cell densitometric analysis. As shown by pseudocolor histograms, the nuclear phospho-p65NFkB expression was more evident in AnnexinV positive cells (green; D vs. C), indicating a selective activation/translocation. (E,F) Quantification of nuclear vs. cytoplasmatic phospho-p65NFkB expression in protein extract fractions upon increasing NGF exposure (24 h). Red dash lines indicate baseline expression (untreated cells). The densitometric analysis was performed specifically on the cropped image (see panel), resulting from the original immunoblot (see Fig. S1), to avoid any artefact in acquisition and data were expressed as compared to untreated ones. Minor brightness/contrast adjustment were performed by photoshop for better image presentation (see cropped panels probed with p65NFkB or actin). Data are mean \pm SEM of three independent experiments. ANOVA analysis followed by Tukey-Kramer post-hoc; sign: ${ }^{\star} p<.05$. Magnifications: $\mathrm{a}-\mathrm{b}, \times 400 ; \mathrm{c}, \times 600$. 


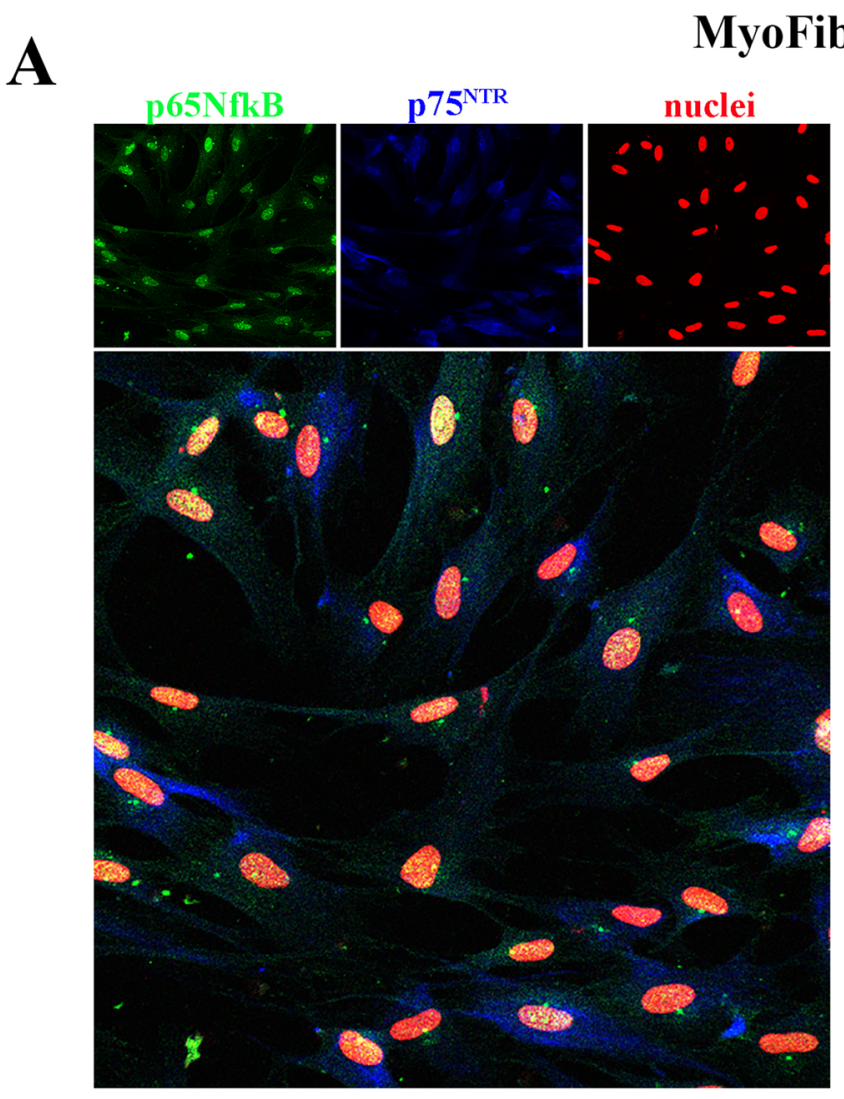

control
MyoFibroblasts
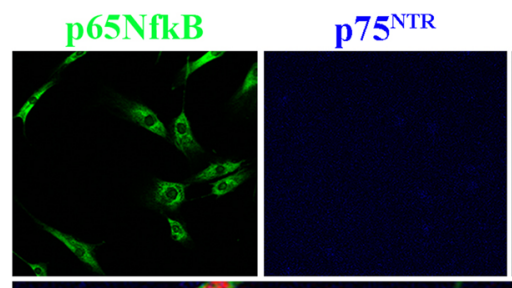

nuclei

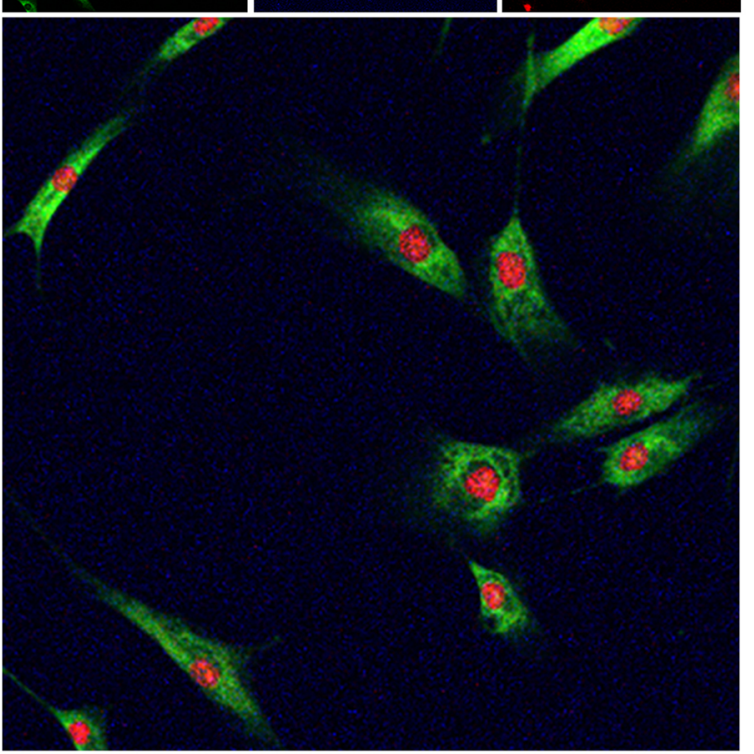

$\alpha \mathbf{p 7 5}^{\mathrm{NTR}}$ neutralization

\section{$+100 \mathrm{ng} / \mathrm{mL}$ NGF}

Figure 3. NGF driven p65NFkB expression/localization. Confocal images of $\mathrm{p} 75^{\mathrm{NTR}}$ siRNA cultures were acquired at $24 \mathrm{~h}$ from NGF stimulation. Representative images of p65NFkB (green) and p $75^{\text {NTR }}$ (blue) immunoreactivity over red nuclei (propidium iodide) of $100 \mathrm{ng} / \mathrm{mL}$ NGF-exposed myofibroblasts, either untreated (A) and p $75^{\mathrm{NTR}}$ oligonucleotides transfected ones $(\mathbf{B})$. Upper squares display single staining. Images are representative of three independent experiments acquired under the same channel-series parameters by confocal microscope Nikon ci and analyzed by NIS software.

plasm and nuclear levels in AnnexinV positive (green/FITC) cells (Fig. 2B). The different AnnexinV (upper frame) and phospho-p65NFkB (lower frame) expression is shown (grayscale of the two cells framed in overlay image is shown in the right side of Fig. 2B). Single cell densitometric analysis was carried out specifically for phospho-p65NFkB in AnnexinV negative and positive cells. A representative expression of different cytoplasm to intracellular localization of phospho-p $65 \mathrm{NFkB}$ is reported, as shown by greyscale acquired and pseudocolors cell images (Fig. 2C,D). As shown by 3D IntDen graphical representation (right) panels, the intranuclear phospho-p65NFkB expression was more evident in AnnexinV positive cells (Fig. 2D) with respect to AnnexinV negative one (Fig. 2C).

Western Blotting analysis confirmed the increased expression and nuclear translocation of phospho-p65NFkB protein, as shown by graphics and a representative immunoblot on both nuclear (Fig. 2E) and cytoplasmic (Fig. 2F) extracts. Quantifications were carried out against untreated nuclear and cytoplasm extracts showing a significant increase in phospho-p65NFkB in nuclear extracts in a dose dependent fashion, as visualized over a baseline dashed line in the bar-graphs $\left({ }^{*} p<.05 \mathrm{in} 100 \mathrm{ng} / \mathrm{mL}\right.$ exposed cells with respect to untreated ones; Fig. 2E). A decrease in cytoplasm expression was monitored, with the lowest expression at $1 \mathrm{ng} / \mathrm{mL}$ NGF, without explanation (Fig. 2F).

Confocal microscopy showed the localization of perinuclear $\mathrm{p} 75^{\mathrm{NTR}}$ and $\mathrm{p} 65 \mathrm{NFkB}$ immunoreactivity inside nuclei after NGF treatment (100 ng/mL; Fig. 3A). By contrary, p $75^{\mathrm{NTR}}$ siRNA (oligonucleotides) transfected myofibroblasts showed a drastic reduction of $\mathrm{p} 75^{\mathrm{NTR}}$ immunoreactivity, which resulted in a retained cytoplasm immunoreactivity of p65NFkB (Fig. 3B). The original immunoblots specific for both cytoplasmatic and nuclear expression phospho p65NFkB are shown in Fig. S1. 

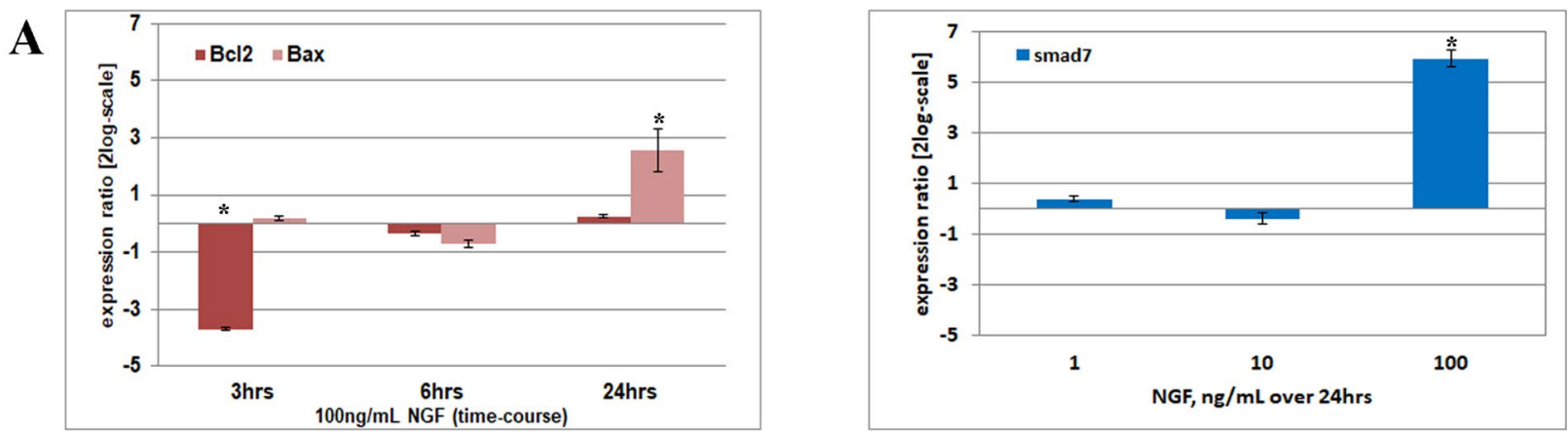

B

Figure 4. $\mathrm{NGF}$ and $\mathrm{Bcl} 2 / \mathrm{Bax}$ associated apoptosis. NGF modulates $\mathrm{Bcl} 2 / \mathrm{Bax}$ transcript ratio (A; time response) and Smad7 (B; dose response) transcript expression. Real time PCR followed by REST-ANOVA coupled analysis are shown for $100 \mathrm{ng} / \mathrm{mL}$ NGF treated cells, as compared to untreated ones. Both significant NGF modulation of Bax transcript and smad7 transcript expression are visible $\left.{ }^{*}\right)$. Note that smad7 works as inhibitory factor of TGF $\beta 1$ signaling. Data are mean \pm SEM (fold changes as log2-expression) of three independent experiments.

NGF modulates Bcl2:Bax ratio and Smad7 transcripts. To explore the possible role of Bcl2 family members in the NGF-induced apoptosis, the effects of NGF on the expression of Bcl2 and Bax protein was examined by real time PCR. Bcl2 and Bax proteins are well-known anti-apoptotic and pro-apoptotic in situ markers, with counteracting effects (Bcl2 acts by blocking Bax-induced apoptosis) ${ }^{20}$. As shown in Fig. 4A, changes in expression of $\mathrm{Bcl} 2$ and $\mathrm{Bax}$ transcripts were monitored upon $100 \mathrm{ng} / \mathrm{mL}$ NGF exposure. Particularly, Bcl2mRNA deregulation was higher at $3 \mathrm{~h}\left(-3.691 \pm 0.037_{\log 2}\right)$ while Bax transcript upregulation $\left(2.547 \pm 0.749_{\log 2},{ }^{*} p<.05\right)$ was maximum at $24 \mathrm{~h}$, as observed by REST-ANOVA coupled analysis on treated versus untreated RNA extracts (Fig. 4A). As shown in Fig. 4B, smad7 transcript (the inhibitory factor of TGF $\beta 1$ signaling) was significantly increased at $24 \mathrm{~h}$ upon $100 \mathrm{ng} / \mathrm{mL}$ NGF exposure $\left(5.946 \pm 3.320_{\log 2},{ }^{*} p<.05\right.$; fold changes vs. untreated expression; REST-ANOVA coupled analysis).

NGF influences myoFBs' protein signature (conditioned media). To identify potential mediator between inflammatory (cytokines, chemokines, adhesion molecules), growth (neurotrophins, fibrogenic and angiogenic factors) and tissue remodeling (TIMPs) ones, potentially produced/released into conditioned media by NGF-exposed myoFBs, a chip array with sixty (60) potential candidates was personalized. According to multiple comparison and Bonferroni's corrections, ANOVA analysis pointed to 3 out of 60 pre-selected candidates. A trend to an increase and significant expression at $10 \mathrm{ng} / \mathrm{mL}$ NGF was observed for IL8 $(p<.001)$ proteins (Fig. 5A,B). A decrease of IL6 was assessed at increasing NGF doses $(p<.01$; Fig. 5C,D). Besides an increase at lower concentration (Fig. 5E), no significant changes were observed for TIMP1 expression (Fig. 5E,F). Protein chip array data (Fig. 5A,C,E) were confirmed by the ELLA microfluidic platform (Fig. 5B,D,F).

NGF increased VEGF and cyr61 proteins/gene transcripts. To verify the NGF contribution in angiogenesis, both VEGF and cyr61 molecules were analyzed in conditioned media (protein) and cell extracts (mRNA). Of interest, specific increase of VEGF protein was quantified at $1 \mathrm{ng} / \mathrm{mL}$ NGF exposure (Fig. 6A), as confirmed by ELISA (data not shown), and sustained by molecular analysis (Fig. 6B). Of interest, a significant increase of cyr61 protein was detected at $10 \mathrm{ng} / \mathrm{mL} \mathrm{NGF}$, as compared to untreated ones $(p<.05$; Fig. 6C) and confirmed by molecular data showing a specific cyr61 mRNA upregulation after $1 \mathrm{ng} / \mathrm{mL}$ NGF exposure $(-2.918$ $\log ; p>.05$, Fig. 6D).

\section{Discussion}

The NGF healing properties have been prospected since 50s', from NGF-driven wound healing under physiological states to tissue repair under acute and chronic inflammatory conditions, either Th1 or Th2 driven ${ }^{6,7}$. Herein, our findings extend previous data on NGF-induced apoptosis in trkA ${ }^{\mathrm{NGFR}} / \mathrm{p} 5^{\mathrm{NTR}}$-bearing and $\alpha \mathrm{SMA}$-expressing myoFBs ${ }^{11}$, by providing evidence on cJun activation, $\mathrm{Bcl} 2$ :Bad ratio reduction (Bad overexpression), p65NFkB nuclear translocation and smad7 overexpression. The protein signature of conditioned media indicates that long-lasting myoFBs synthesize and release IL8 and VEGF as well as cyr61. Of interest, IL6 and TIMP1 were significantly deregulated.

A graphical explanation of these findings is shown in Fig. 7. Prolonged stimulation might trigger survival of myoFBs and inappropriate ECM remodeling (overt fibrosis), causing irreversible alterations of organ anatomy and function ${ }^{21-23}$. Apoptotic process represents a physiological strategy removing long-lasting myoFBs, the source of ECM deposition and prolonged matrix contraction ${ }^{2,3,20,24}$. We previously showed the profibrogenic NGF effects on primary cultures of FBs outgrew from skin, lung and conjunctival/corneal tissue (NGF/TGF $\beta 1$ expression, aSMA protein metabolism and contractive activity) ${ }^{11}$. Subsequently, we observed that NGF-treated myoFBs showed apoptosis restricted to a $75^{\mathrm{NTR}}$ expressing myoFB phenotype, an effect that was counteracted by specific trkA ${ }^{\mathrm{NGFR}}$ and/or $\mathrm{p} 75^{\mathrm{NTR}}$ inhibitors ${ }^{11,25}$. Herein, our findings point at the NGF-mediated cJun increase and $\mathrm{Bcl} 2 ; \mathrm{Bax}$ ratio decrease in apoptotic myoFBs, supporting previous studies on $\mathrm{p} 5^{\mathrm{NTR}}$-transduced apoptosis in association with Rac-GTPase and c-Jun activation ${ }^{26}$. The observation of a decreased Bcl2:Bax ratio in Annexin 


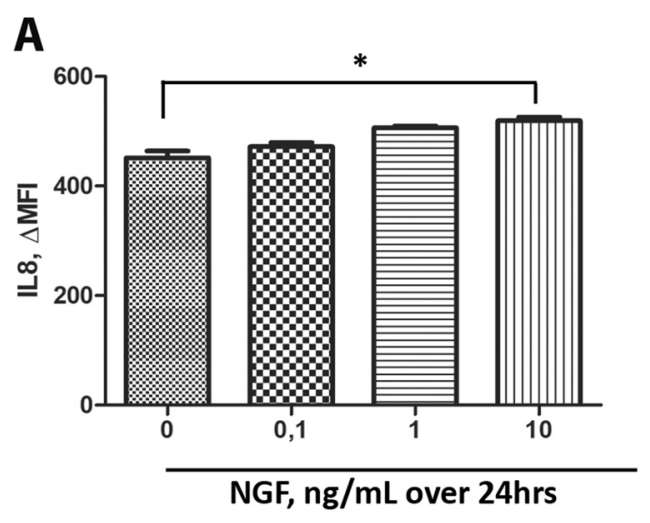

C

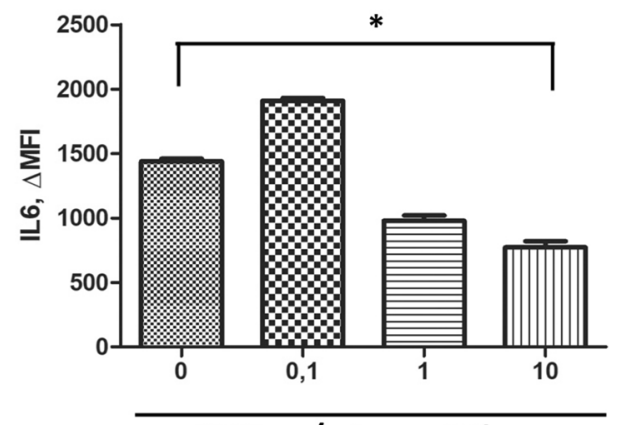

$\mathrm{NGF}, \mathrm{ng} / \mathrm{mL}$ over $24 \mathrm{hrs}$

$\mathbf{E}$

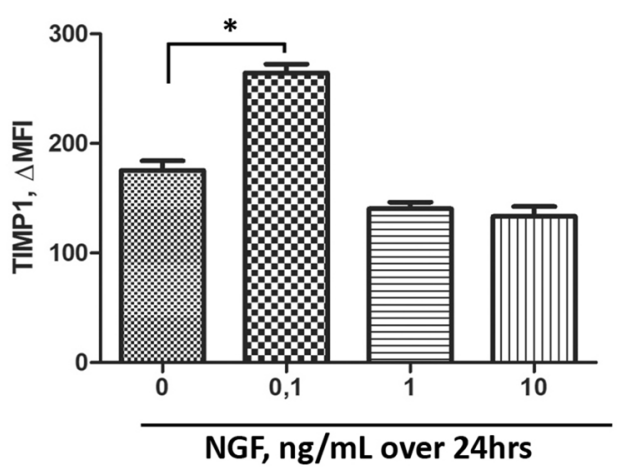

B

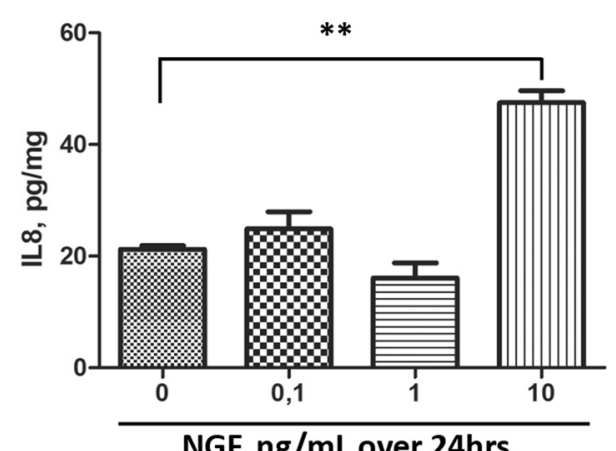

D

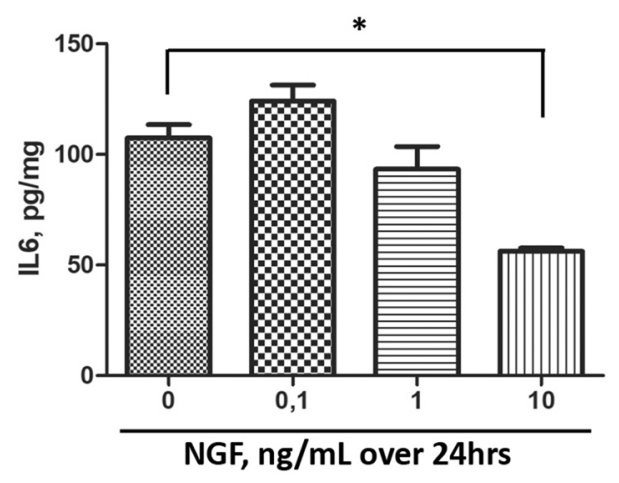

$\mathbf{F}$

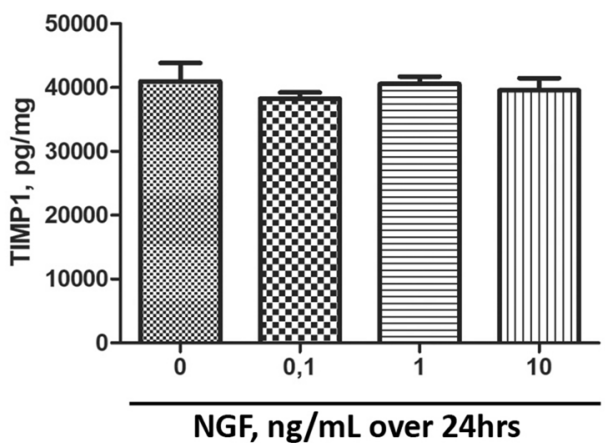

Figure 5. Overview of the in vitro results obtained by microarray chip analysis and ELLA microfluidic assay. Bar-graph showing the expression of IL8 $(\mathbf{A}, \mathbf{B}), \operatorname{IL6}(\mathbf{C}, \mathbf{D})$ and TIMP1 $(\mathbf{E}, \mathbf{F})$ in conditioned media from myoFBs exposed to increasing NGF doses $(0-10 \mathrm{ng} / \mathrm{mL})$. Note the increase of IL8, the decrease of IL6 and the quite unchanged expression of TIMP1. Data are mean \pm SEM (fold changes or $\mathrm{pg} / \mathrm{mL}$ ) of three independent experiments. ANOVA analysis followed by Tukey-Kramer post-hoc; sign: ${ }^{\star} p<.05$ and ${ }^{* *} /<.01$, as for multiparametric array analysis.

positive myoFBs would suggest that $\mathrm{Bcl} 2$ :Bax ratio might serve as a rheostat to determine the susceptibility to death process ${ }^{27-29}$. Our NGF-mediated apoptotic effect was also associated with p65NFkB nuclear translocation. $\mathrm{NFkB}$ transcription factor is composed of p50/p65 subunits close to cytoplasmic IkB inhibitors to prevent nuclear translocation, a route observed in several cell types in the presence of the pan-neurotrophin p75 ${ }^{\mathrm{NTR}}$ receptor activation $^{30,31}$. Our finding on NGF-mediated $\mathrm{p} 65-\mathrm{NFkB}$ nuclear translocation in these myoFBs strongly suggest the ability of NGF to increase myoFB apoptosis while in unresponsive myoFBs it might modulate the release of some proinflammatory as well as pro-angiogenic factors, through a $\mathrm{p} 75^{\mathrm{NTR}}$ mediated signal ${ }^{11}$. The $\mathrm{p} 75^{\mathrm{NTR}}$ neutralization showed a retaining in p65NFkB translocation, corroborating the NGF/p $75^{\mathrm{NTR}}$ specific involvement. We hypothesize that the unresponsive cells were those with a lower trk $\mathrm{A}^{\mathrm{NGFR}} / \mathrm{p} 75^{\mathrm{NTR}}$ ratio (likewise with high Bcl2:Bax ratio).

It is noteworthy highlight that tissues remodeling is strongly driven by TGF $\beta 1$ working on a microenvironment enriched of others profibrogenic mediators released by accessory and immune cells, epithelial and endothelial cells and even activated myoFBs ${ }^{13,17}$. The profibrogenic TGF $\beta 1-$ RI/RII routes the down streaming of smad2/3 and smad4 activation in the presence of a blocked Smad7 activity ${ }^{32,33}$. As observed in this in vitro 
A

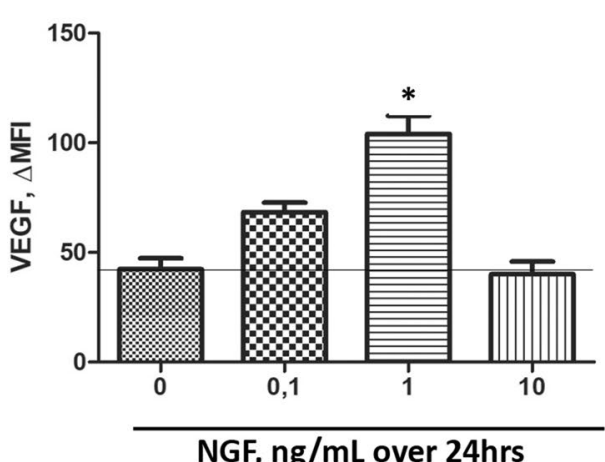

C

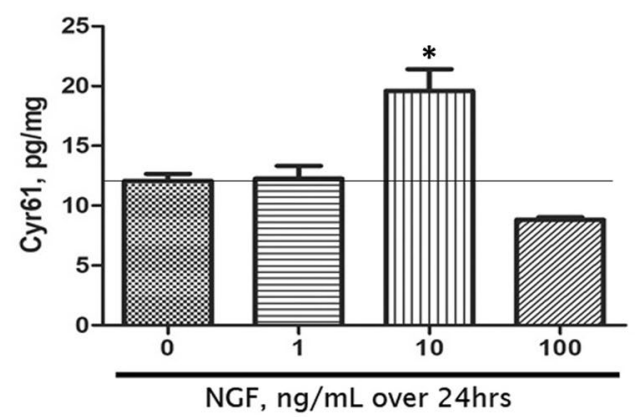

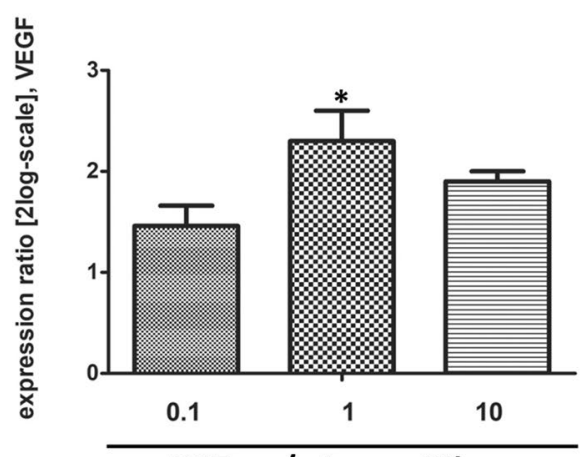

NGF, ng/mL over $24 \mathrm{hrs}$

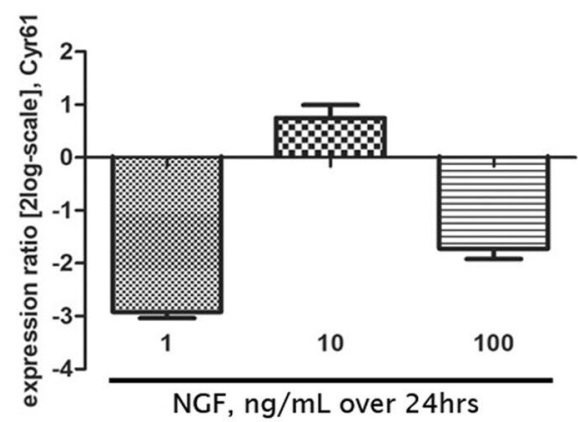

Figure 6. NGF triggers VEGF and cyr61 transcript/protein expression. Protein quantification $(\mathbf{A}, \mathbf{C})$ and transcript amplification (B,D) specific for VEGF and Cyr61. (A,B) Bar-graph showing the expression of VEGF: note the higher protein expression after $1 \mathrm{ng} / \mathrm{mL}$ NGF exposure, as confirmed at the biomolecular levels. (C,D) Bar-graph showing the expression of cyr61: note the higher protein expression at $10 \mathrm{ng} / \mathrm{mL}$ NGF dose, as confirmed by biomolecular analysis. Data are mean \pm SEM (MFI or $\mathrm{pg} / \mathrm{mL}$ for proteins and fold changes as $\log 2$-expression for transcripts) of three independent experiments. ANOVA analysis followed by Tukey-Kramer post-hoc; sign: ${ }^{\star} p<.05$ and ${ }^{* *} p<.01$, as for multiparametric array analysis.

model, NGF might dampen TGF $\beta 1$ signaling thought activation of smad7 expression, explaining at least in part the physiological remodeling observed upon exogenous addition of NGF (corneal ulcers' closure) ${ }^{10}$. As known, smad7 works as an inhibitory factor in TGF $\beta 1$ pathway, the Smad7 expression in these myoFBs might justify at least in part the absence of insistent myoFB signaling in human tissues when repair is NGF assisted ${ }^{32}$. As illustrated in Fig. 7, exogenous NGF administration (shorten as + NGF in red) might revert Bcl2:Bax ratio of fibrotic myoFBs and promote $\mathrm{p} 65 \mathrm{NFkB}$ nuclear translocation restoring physiological condition and function of tissue, with resolution of fibrosis.

To identify potential mediator between inflammatory (cytokines, chemokines, adhesion molecules), growth (neurotrophins, fibrogenic and angiogenic factors) and tissue remodeling ones, we used a customized array chip approach with the screening of 60 potential candidates, as previously tested in other studies ${ }^{34}$. Herein, the increased expression of IL8 and the decreased expression of IL6, as detected in conditioned media of NGFexposed myoFBs, would imply that NGF does not contribute to the profibrogenic microenvironment.

The dual-faced of angiogenesis at induction of fibrogenesis and resolution of fibrosis has been described in the last years ${ }^{35,36}$. Angiogenesis-the formation of new blood vessels from pre-existing vessels-is a complex and dynamic process occurring both physiologically and pathologically ${ }^{37}$. The tissue healing with proper matrix remodelling would benefit from a controlled induction of vascular activity. A controlled apoptosis and a tidy epithelia-stroma interaction should occur at involved and uninvolved surrounding tissues ${ }^{36,37}$. Some recent evidence suggested that experimental inhibition of angiogenesis ameliorates the development of liver fibrosis, while other recent studies indicate that neutralization or genetic ablation of VEGF can delay tissue repair and fibrosis resolution in damaged tissues ${ }^{38,39}$. The imbalance between pro/anti- angiogenic mediators might contribute to apoptotic or sustain the process of fibrosis, as observed for CCN1/CYR61 involved in attenuating and/or scavenging of TGF $\beta$, mitigating the process of fibrogenesis ${ }^{13,40,41}$. The findings herein reported suggest that the NGF mechanisms might involve a deregulation of TGF $\beta 1$ signalling, due to Smad7 gene expression, and alternative a VEGF/cyr61 activation ${ }^{17,32,41}$.

Some open questions still persist (1) as in vitro study on TGF $\beta 1$-induced myoFBs, and as known TGF $\beta 1$ does not represent the lone differentiating factor in vivo and other soluble mediators can trigger this differentiation; (2) the trkA $\mathrm{A}^{\mathrm{NGFR}} / \mathrm{p} 75^{\mathrm{NTR}}$ heterodimer distribution on cell membrane, as other trkA $\mathrm{A}^{\mathrm{NGFR}} / \mathrm{trkA}^{\mathrm{NGFR}}$ and $\mathrm{p} 75^{\mathrm{NTR} /}$ p $75^{\text {NTR }}$ homodimers can also occur influencing the cellular pathway and finally (3) this NGF-driven p65 NFkB translocation could result in three different pathways (the canonical, the non-canonical, and the atypical one) 
A

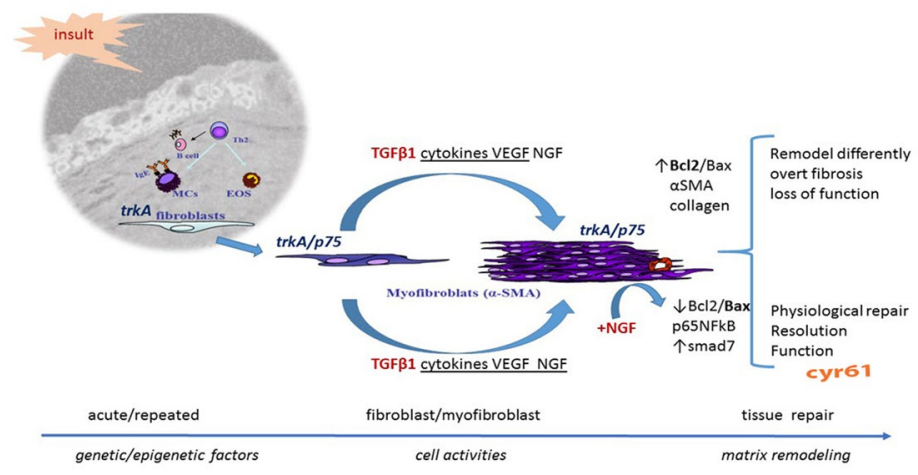

Figure 7. Graphical sketch for a possible explanation for the finding on induced myoFBs upon NGF exposure. In injured tissues, trkA $\mathrm{NGFR}^{\mathrm{NG}} \mathrm{p} 75^{\mathrm{NTR}}$ - myoFBs arising from resident "quiescent" trkA ${ }^{\mathrm{NGFR}}$-FBs (fibroblasts), mainly upon TGF $\beta 1$ stimulation and a specific microenvironment, achieve appropriate tissue remodeling (collagen production, ECM refining and contraction). NGF might function as a modulator, in concert with a plethora of inflammatory and matrix remodeling mediators. Overt fibrosis indicates a not well-balanced tissue remodeling. As known, smad7 works as an inhibitory factor in TGF $\beta 1$ pathway. Exogenous NGF administration (shorten as $+\mathrm{NGF}$ in red) might revert $\mathrm{Bcl} 2 / \mathrm{Bax}$ ratio and promotes p65NFkB nuclear translocation restoring physiological condition and function of the tissue, with the resolution of fibrosis. As pleiotropic factor, NGF can also drive neovessel formation and trough VEGF and cyr61 (red) modulation, it might contribute to functional recovery. For representative purpose (on left upper side), a B/W image (a conjunctival frame from a section belonging to a very old historical collection; Anatomia Patologica, Università Cattolica del Sacro Cuore) as background for layered inflammatory cells. Illustration was developed on Microsoft Office Power Point 365 software (Microsoft corp., New York, NY, USA).

depending on various upstream activating signals (TNFa, Interleukins, LPS/LT, UV and NO), influencing the entity of $\mathrm{Bcl} 2$ :Bax ratio ${ }^{42}$. On the contrary, the possibility to use topical NGF will reduce all the disappointed effects played by the circulating addition of NGF.

Taken together, several mediators of inflammation and tissue remodelling, either endogenous or exogenously administered (including natural (omega 3/5) and synthetic ones), might participate in the myoFB-driven remodelling differentially over again, representing candidate factors for driving the correct repair ${ }^{43}$. The NGF-driven upregulation of smad7, an inhibitory component of TGF $\beta 1$ pathway, and VEGF/cyr61 deserve further investigation, as opening to alternative approaches in counteracting fibrosis, especially for fibrotic eye diseases.

\section{Data availability}

All data are available in the manuscript.

Received: 6 May 2020; Accepted: 31 December 2020

Published online: 18 January 2021

\section{References}

1. Lorena, D. et al. Normal scarring: importance of myofibroblasts. Wound Repair Regen. 10, 86-92. https://doi.org/10.1046/j.1524475x.2002.00201.x (2002).

2. Wynn, T. A. Cellular and molecular mechanisms of fibrosis. J. Pathol. 214, 199-210. https://doi.org/10.1002/path.2277 (2008).

3. Greenhalgh, D. G. The role of apoptosis in wound healing. Int. J. Biochem. Cell. Biol. 30, 1019-1030. https://doi.org/10.1016/s1357 -2725(98)00058-2 (1998).

4. Sofroniew, M. V., Howe, C. L. \& Mobley, W. C. Nerve growth factor signaling, neuroprotection, and neural repair. Ann. Rev. Neurosci. 24, 1217-1281. https://doi.org/10.1146/annurev.neuro.24.1.1217 (2001).

5. Matsuda, H. et al. Role of nerve growth factor in cutaneous wound healing: accelerating effects in normal and healing-impaired diabetic mice. J. Exp. Med. 187, 297-306. https://doi.org/10.1084/jem.187.3.297 (1998).

6. Micera, A. et al. New insights on the involvement of Nerve Growth Factor in allergic inflammation and fibrosis. Cytokine Growth Factor Rev. 14, 369-374. https://doi.org/10.1016/s1359-6101(03)00047-9 (2004).

7. Micera, A. et al. Nerve growth factor involvement in the visual system: implications in allergic and neurodegenerative diseases. Cytokine Growth Factor Rev. 15, 411-417. https://doi.org/10.1016/j.cytogfr.2004.09.003 (2004).

8. Micera, A. et al. Nerve growth factor displays stimulatory effects on human skin and lung fibroblasts, demonstrating a direct role for this factor in tissue repair. Proc. Natl. Acad. Sci. USA 98, 6162-6167. https://doi.org/10.1073/pnas.101130898 (2001).

9. Micera, A. et al. The pro-fibrogenic effect of nerve growth factor on conjunctival fibroblasts is mediated by transforming growth factor-beta. Clin. Exp. Allergy 35(5), 650-656. https://doi.org/10.1111/j.1365-2222.2005.02241.x (2005).

10. Bonini, S. et al. Topical treatment with nerve growth factor for neurotrophic keratitis. Ophthalmology 107, 1347-1351. https://doi. org/10.1016/s0161-6420(00)00163-9 (2000) (discussion 1351-1352).

11. Micera, A. et al. Chronic nerve growth factor exposure increases apoptosis in a model of in vitro induced conjunctival myofibroblasts. PLoS ONE 7(10), e47316. https://doi.org/10.1371/journal.pone.0047316 (2012).

12. Micera, A. et al. Nerve growth factor effect on human primary fibroblastic-keratocytes: possible mechanism during corneal healing. Exp. Eye Res. 83, 747-757. https://doi.org/10.1016/j.exer.2006.03.010 (2006). 
13. Desmoulière, A. et al. Transforming growth factor-beta 1 induces alpha-smooth muscle actin expression in granulation tissue myofibroblasts and in quiescent and growing cultured fibroblasts. J. Cell. Biol. 122(1), 103-111. https://doi.org/10.1083/ jcb.122.1.103 (1993).

14. Calza, L., Giardino, L., Giuliani, A., Aloe, L. \& Levi-Montalcini, R. Nerve growth factor control of neuronal expression of angiogenetic and vasoactive factors. Proc. Natl. Acad. Sci. USA 98(7), 4160-4165. https://doi.org/10.1073/pnas.051626998 (2001).

15. Romon, R. et al. Nerve growth factor promotes breast cancer angiogenesis by activating multiple pathways. Mol. Cancer $\mathbf{9}, 157$. https://doi.org/10.1186/1476-4598-9-157 (2010).

16. Wang, J. et al. NGF increases VEGF expression and promotes cell proliferation via ERK1/2 and AKT signaling in Müller cells. Mol. Vis. 22, 254-263 (2016).

17. Kurundkar, A. R. et al. The matricellular protein CCN1 enhances TGF- $\beta 1 /$ SMAD3-dependent profibrotic signaling in fibroblasts and contributes to fibrogenic responses to lung injury. FASEB J. 30(6), 2135-2150. https://doi.org/10.1096/f. 201500173 (2016).

18. Balzamino, B. O. et al. Characterization of NGF, trkA (NGFR), and p75 (NTR) in retina of mice lacking reelin glycoprotein. Int. J. Cell Biol. 2014, 725928. https://doi.org/10.1155/2014/725928 (2014).

19. Pfaffl, M. W. A new mathematical model for relative quantification in real-time RT-PCR. Nucleic Acids Res. 29(9), e45. https://doi. org/10.1093/nar/29.9.e45 (2001).

20. Lagares, D. et al. Targeted apoptosis of myofibroblasts with the BH3 mimetic ABT-263 reverses established fibrosis. Sci. Transl. Med. 9, eaa13765. https://doi.org/10.1126/scitranslmed.aal3765 (2017).

21. Chou, T. T., Trojanowskim, J. Q. \& Leem, V. M. A novel apoptotic pathway induced by nerve growth factor-mediated TrkA activation in medulloblastoma. J. Biol. Chem. 275, 565-570. https://doi.org/10.1074/jbc.275.1.565 (2000).

22. Fukuda, K., Kumagai, N., Fujitsu, Y. \& Nishida, T. Fibroblasts as local immune modulators in ocular allergic disease. Allergol. Int. 55, 121-129. https://doi.org/10.2332/allergolint.55.121 (2006).

23. Lambiase, A. et al. Expression of nerve growth factor receptors on the ocular surface in healthy subjects and during manifestation of inflammatory diseases. Invest. Ophthalmol. Vis. Sci. 39, 1272-1275 (1998).

24. Hinz, B. \& Lagares, D. Evasion of apoptosis by myofibroblasts: a hallmark of fibrotic diseases. Nat. Rev. Rheumatol. 16, 11-31. https ://doi.org/10.1038/s41584-019-0324-5 (2020).

25. Micera, A. et al. Nerve growth factor has a modulatory role on human primary fibroblast cultures derived from vernal keratoconjunctivitis-affected conjunctiva. Mol. Vis. 13, 981-987 (2007).

26. Harrington, A. W., Kim, J. Y. \& Yoon, S. O. Activation of Rac GTPase by p75 is necessary for c-jun N-terminal kinase-mediated apoptosis. J. Neurosci. 22(1), 156-166. https://doi.org/10.1523/JNEUROSCI.22-01-00156.2002 (2002).

27. Zhou, Y. et al. Inhibition of mechanosensitive signaling in myofibroblasts ameliorates experimental pulmonary fibrosis. J. Clin. Invest. 123, 1096-1108. https://doi.org/10.1172/JCI66700 (2013).

28. Nechushtan, A. et al. Bax and Bak coalesce into novel mitochondria-associated clusters during apoptosis. J. Cell. Biol. 153, 12651276. https://doi.org/10.1083/jcb.153.6.1265 (2001).

29. Kane, D. J. et al. Bcl-2 inhibition of neural death: decreased generation of reactive oxygen species. Science 262, 1274-1277. https ://doi.org/10.1126/science.8235659 (1994).

30. Giridharan, S. \& Srinivasan, M. Mechanisms of NF-кB p65 and strategies for therapeutic manipulation. J. Inflamm. Res. 11, 407-419. https://doi.org/10.2147/JIR.S140188 (2018).

31. Chen, Y. et al. P75 Involved in the ubiquitination of a-synuclein in Rotenone-based Parkinson's disease models. Neuroscience 388, 367-373. https://doi.org/10.1016/j.neuroscience.2018.07.048 (2018).

32. Saika, S. et al. Expression of Smad7 in mouse eyes accelerates healing of corneal tissue after exposure to alkali. Am. J. Pathol. 166(5), 1405-1418. https://doi.org/10.1016/S0002-9440(10)62358-9 (2005).

33. Chen, H. B. et al. Nuclear targeting of transforming growth factor-beta-activated Smad complexes. J. Biol. Chem. 280(22), 2132921336. https://doi.org/10.1074/jbc.M500362200 (2005).

34. Micera, A. et al. Quiescent and active tear protein profiles to predict vernal keratoconjunctivitis reactivation. Biomed. Res. Int. 2016, 9672082. https://doi.org/10.1155/2016/9672082 (2016).

35. Wyn, T. A. Cellular and molecular mechanisms of fibrosis. J. Pathol. 214(2), 199-210. https://doi.org/10.1002/path.2277 (2008).

36. Johnson, A. \& Di Pietro, L. A. Apoptosis and angiogenesis: an evolving mechanism for fibrosis. FASEB J. 27(10), 3893-3901. https ://doi.org/10.1096/fj.12-214189 (2013).

37. Park, S. et al. Differential roles of angiogenesis in the induction of fibrogenesis and the resolution of fibrosis in liver. Biol. Pharm. Bull. 38(7), 980-985. https://doi.org/10.1248/bpb.b15-00325 (2015).

38. Zhao, T. et al. Vascular endothelial growth factor-D mediates fibrogenic response in myofibroblasts. Mol. Cell. Biochem. 413(1-2), 127-135. https://doi.org/10.1007/s11010-015-2646-1 (2016).

39. Sakata, K. et al. Neovessel formation promotes liver fibrosis via providing latent transforming growth factor- $\beta$. Biochem. Biophys. Res. Commun. 443(3), 950-956. https://doi.org/10.1016/j.bbrc.2013.12.074 (2014).

40. Borkham-Kamphorst, E. et al. The anti-fibrotic effects of CCN1/CYR61 in primary portal myofibroblasts are mediated through induction of reactive oxygen species resulting in cellular senescence, apoptosis and attenuated TGF- $\beta$ signalling. Biochem. Biophys. Acta 1843(5), 902-914. https://doi.org/10.1016/j.bbamcr.2014.01.023 (2014).

41. Lau, L. F. CCN1/CYR61: the very model of a modern matricellular protein. Cell. Mol. Life Sci. 68(19), 3149-3163. https://doi. org/10.1007/s00018-011-0778-3 (2011).

42. Sakowicz, A. et al. Canonical, non-canonical and atypical pathways of nuclear factor кb activation in preeclampsia. Int. J. Mol. Sci. 21, 5574. https://doi.org/10.3390/ijms21155574 (2020).

43. Nicolai, E. et al. Omega-3 and Omega- 6 fatty acids act as inhibitors of the matrix metalloproteinase- 2 and matrix metalloproteinase-9 activity. Protein J. 36, 278-285. https://doi.org/10.1007/s10930-017-9727-9 (2017).

\section{Acknowledgements}

GE, BOB, AM are grateful to Fondazione Roma (Italy) for continuous support. This study was presented in part at the 2016 Association for Research in Vision and Ophthalmology meeting in Fort Lauderdale, Florida.

\section{Author contributions}

G.E. and A.M. conceived and designed the experiments. G.E., B.O.B., E.S., F.B. and A.M. performed the experiments. G.E., B.O.B., A.M. analyzed the data. A.M. contributed reagents/materials/analysis tools. G.E., B.O.B. and A.M. wrote the paper; G.E., A.U. and A.M. revised the paper.

\section{Funding}

Italian Ministry of Health (RC263504; RC2761596).

\section{Competing interests}

The authors declare no competing interests. 


\section{Additional information}

Supplementary Information The online version contains supplementary material available at https://doi. org/10.1038/s41598-021-81040-x.

Correspondence and requests for materials should be addressed to A.M.

Reprints and permissions information is available at www.nature.com/reprints.

Publisher's note Springer Nature remains neutral with regard to jurisdictional claims in published maps and institutional affiliations.

(c) (i) Open Access This article is licensed under a Creative Commons Attribution 4.0 International cc) License, which permits use, sharing, adaptation, distribution and reproduction in any medium or format, as long as you give appropriate credit to the original author(s) and the source, provide a link to the Creative Commons licence, and indicate if changes were made. The images or other third party material in this article are included in the article's Creative Commons licence, unless indicated otherwise in a credit line to the material. If material is not included in the article's Creative Commons licence and your intended use is not permitted by statutory regulation or exceeds the permitted use, you will need to obtain permission directly from the copyright holder. To view a copy of this licence, visit http://creativecommons.org/licenses/by/4.0/.

(C) The Author(s) 2021 